\title{
Some observations on waterslide injuries
}

\author{
David J Ball
}

\begin{abstract}
Study objective-To investigate the causes of a series of interperson collisions on a waterslide resulting in serious injury, and to assess adequacy of control systems and legal liability.

Method-Site investigation of operating characteristics including a traffic light controlled system, organisational safety culture, and user behaviour.

Results-Despite a battery of safety features including closed circuit TV, citizen's band radios, a traffic light controlled system, part time supervision, and warning notices, the system was found to be inherently "unsafe" as operated. It placed a small but significant percentage of users in a hazardous situation whereby consecutive riders could collide with each other while in the flume even when conforming with all instructions. The realised risk might have been even higher were not staff and users adopting their own precautionary measures.

Conclusions-The risk to waterslide users, even the majority observing the safety rules, was questionably high, and facility operators were vulnerable to a court ruling that they had failed in their duty of care. It is suggested that waterslide operators elsewhere, who are wholly or partially reliant on traffic light controlled systems, should carefully scrutinise the safety of their operating systems. Members of the public who use these facilities would, in any event, be well advised to remain vigilant whatever the perceived adequacy of the safety system in operation.
\end{abstract}

(Injury Prevention 1998;4:225-227)

Keywords: waterslide; flume; duty of care; risk compensation

Waterslides are now well established features at many swimming pools and leisure complexes. In the UK alone there are over 300 facilities. With growth in popularity, however, sporadic stories of injuries have appeared in the popular press and occasionally in journals describing individual case histories. ${ }^{12}$ These have been supplemented by more comprehensive reviews of waterslide safety measures and associated risks based on data extracted from ad hoc surveys of facilities or from national injury surveillance systems. ${ }^{34}$

This case study is somewhat different, being rooted in an investigation after the event of a series of injuries and near misses to waterslide users at a particular establishment. Despite the specificity of the investigation, it is believed that there is a more general message for waterslide operators, particularly those placing some degree of reliance on traffic light controlled systems for maintaining user separation.

\section{Method}

The investigation concerned a pair of enclosed, 90 metre long waterslides at a community swimming pool. It was prompted by an incident in which a teenage boy was struck from behind while descending one of the flumes by a $90 \mathrm{~kg}$ adult travelling at an estimated speed of 9 metres per second. The collision resulted in an upper limb fracture and bruising. The adult reported no significant injuries.

Only cursory examination of the accident book for the facility was possible, but from that and other information it became apparent that 10 other actual or near collisions in the flumes had occurred during the preceding three month period, a figure that one suspects may be subject to considerable under-reporting. Most of these incidents appeared to involve either children or adolescents as one of the victims, though this was not exclusively the case. As a comparison, throughput on the flumes has been estimated as in the region of 500000 descents per annum.

To determine the causes of these incidents and to assess the safety of the system, staff and victims were interviewed, and the system's functioning and safety features studied during two days of routine operation.

\section{Results}

SAFETY FEATURES

Access to the flumes was by a spiral staircase with signage at the bottom and top advising would-be users that they should be of appropriate health, age (over 8 years), and swimming prowess, and that they should observe certain rules, including feet first entry into the flumes, riding on the back, and not kneeling, sitting, riding in pairs, or entering before a warning traffic light had turned green.

At all times the lower splash pool was monitored by a lifeguard, and at busy times a further attendant was present at the flume entry points. Attendants were able to contact each other via citizen's band radio, and any attendant at the flume entry point could, if desired, observe the exit pools via closed circuit TV.

The primary safety features, however, were traffic lights mounted above each flume entry point. As remarked above, users were instructed to wait for a green light before entering the flume. Upon entry, a light sensor recorded the presence of a user and tripped the light to red. This would not turn green again
Correspondence to: Professor Ball.
Biological and University, 10 Highgat Hill, London N19 5ND, 
until a sensor lower down the flume was passed by the occupant and a further, electronically programmed, three second time delay had elapsed. The lower sensors were located about two thirds of the way down the flumes.

FLUME TRAVEL TIMES

As it was not disputed that the adult involved in the particular collision which prompted this study had waited for the green light before entering the flume, the key question was whether it was reasonably foreseeable that a collision could none the less arise in the flume given the positioning of the lower sensor and the electronic time delay.

Many measurements were made of descent patterns during the two day study, but those most pertinent to this issue consisted of timings of a random sample of 250 users to descend the full length of the flumes, together with a further set of timings of the period between the light turning to green, equivalent to three seconds after the lower sensor was passed, and the occupant emerging from the bottom of the flume. The measurements were made on week days during summer and in school vacation time when they were moderately busy with occasional short queues at the flume entrances.

The mean transit time of the fastest descents (top 10\%) for the full length of the flumes was approximately 13 seconds in one case and 16 seconds in the other. Bearing in mind the three second time delay in the warning system, this implied that anyone taking in the region of about 15 to 20 seconds or more to transit the section of the flumes below the lower sensors was vulnerable to being struck from behind, either in the flume itself or in the splash pool, if followed by a person executing a rapid descent.

The measurements of transit times in the lower section showed that for a large majority of users this was about 5 seconds, hence providing what should be ample spacing between descents. However, even with this relatively modest study sample, three persons were sufficiently slow over the final section, taking 15,16 , and 24 seconds, to be exposed to a hazardous situation.

\section{Discussion}

The evidence thus suggests prima facie that of the order of $1 \%$ of descents under the extant regime presented a hazard of interperson collision. For a regular user undertaking, say, five descents in an hour this would be equivalent to a probability of exposure to a hazardous situation of the order of 5000 per 100000 hours of participation. The degree of risk itself depends, however, upon a number of other factors besides the distribution of travel times and the position and time delay of the sensors. For instance, it is necessary for a queue, however short, to have formed at the flume entrance and moreover that a slow descent is followed by a rapid descent. The data, shown in fig 1 as cumulative frequency plots, suggest that about a fifth of descent times might be classed as rapid, being within 1 or 2 seconds of the fastest descents, so the risk of a hazardous situation

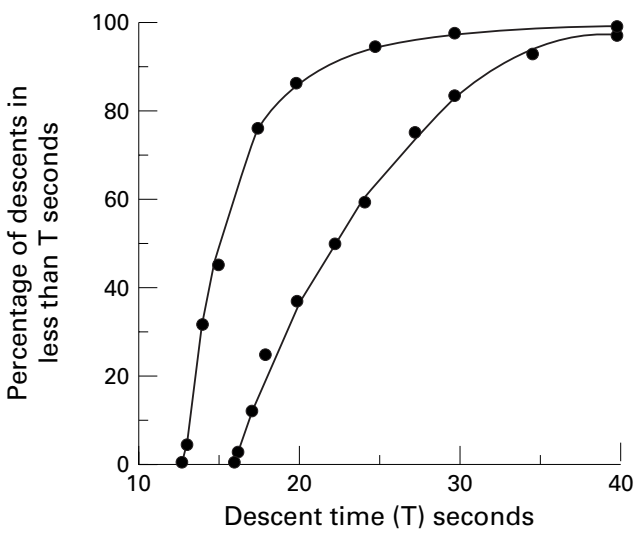

Figure 1 Frequency plot of total descent times for the two waterslides.

overall would be reduced to about 1000 per 100000 hours of participation.

By most standards this is a high degree of risk exposure. For instance, even for contact sports like soccer and rugby, acknowledged as risky, (non-fatal) accident rates are a fraction of this value. ${ }^{56}$ Further, the consequences of interperson collisions on the flumes is potentially severe, particularly considering that the facility was open to the general public and not restricted to the fittest and more resilient. This suggests that the risk on the flumes is at a design level that might well be judged intolerable by a regulator or court.

In practice, however, it seems likely that the actual risk was somewhat lower. For instance, a simple calculation based on daily usage suggests that with a $0.2 \%$ risk factor per descent one might expect an average of three collisions or near misses per day, which is considerably higher than the available, though limited, evidence suggests. There are several reasons why this might be so.

One is that the risk is only present during busy times when queuing occurs at the top. In addition, interviews with staff and observations of behaviour suggest that voluntary risk mitigation behaviour by some of those involved in using and controlling the system may be a factor. Thus, interviews with attendants at the waterslide indicated a lack of trust in the traffic light controlled system and a distinct preference for the closed circuit TV when this was operational. Use of the closed circuit TV would, of course, ensure that no two users were in a flume simultaneously. Observation of flume users at the point of entry also suggested a lack of trust by users in the traffic lights, because many allowed an extra time interval after the lights had changed before descending. Whether consciously or subconsciously, this behaviour would have served to reduce risk.

Interestingly, the senior management of the facility did not share this caution. Their view was firmly that the facility was safe as designed and that any accidents that did occur in the flume must be attributable to misbehaviour. This belief in the system's invulnerability appeared to be linked to a statement by the manufacturer to the effect that the system was an entirely safe one which could never lead to interperson collisions. It can be gleaned from 
the following statement by the insurers of the facility that they held similar views: "... the TV camera is only an additional device to improve communication between the landing pool and the flume tower, and its not being on in no way affects the safety of the ride itself". From this one might deduce that a communication gap existed between senior managers who were more remote from day to day operation, and poolside staff, the one believing in the infallibility of the system, and the other being less sanguine having noted the realities of operation. The existence of gaps in communication in the management of risk is a widespread and well known phenomenon. ${ }^{7}$

It is of interest to note that advice has been published on the desired separation of flume riders. Stevens and Jenkins recommend as follows": "In order to reduce the number of collisions on slides, SAIL (Safety in Leisure Research Unit) advocates that the safest method is not to release the top rider until the descending rider has reached the exit area. However, in slides where this is operated the result has been to produce a slide which is unexciting: too long is spent queuing and as a result excitement is removed from the slide ride. It is also an uneconomic way of running a slide when a slide is used as a main attraction and volume of traffic/throughput cannot be achieved".

The authors go on to recommend that a critical point on the slide be used as a marker, which must be passed by one rider before the next is admitted, in order to avoid collisions, rather than the use of time interval separation alone, although they say that the latter is perceived as constituting good practice.

The conclusion from this investigation is, however, that neither of these methods is adequate for this and similar systems, and that the only way to ensure a reasonable level of public safety is to avoid dual occupancy of flumes. Arguments based on queuing, which is common at public venues of disparate natures and does not appear to detract unreasonably from enjoyment, and commercial interests, are unlikely to hold much sway in court cases dealing with the occurrence of injuries, where decision criteria are more likely to relate to foreseeability of hazards, the reasonable practicability of safety measures, and the vulnerability of those exposed. $^{8}$

With regard to the latter, the three slowest transit times in this sample were recorded by a teenage girl, a mid-aged woman, and a mid-aged man, none of whom was in any way misusing the system. Indeed, with any sports facility that caters for the general public rather than the elite alone, design considerations need to encompass the less able and timid, who as in these examples can be fully expected to try to engineer slower descents. Anyone who has used a waterslide will know that this is possible, simply by exerting pressure with the hands on the flume floor or by partially raising the back, but this is difficult to control and may even bring an inexperienced user to a dead halt, guaranteeing a long residence time in the flume. It is suggested that such behaviour by the public at large has to be anticipated and therefore allowed for in system design and operation.

1 Davies PDO. Water slide aquaplaning injury. $B M \mathcal{F}$ 1990;300:1401.

2 Niv J, Lessing JB, Hartuv J, et al. Vaginal injury resulting 1992;166:930-1.

3 Stevens TR, Jenkins IS. Improving the safety of waterslides. West Glamorgan Institute of Higher Education, Swansea, UK: Safety in Leisure Research Unit, 1990.

4 Gerritse JC, van Wepperen W. The safety of waterslides. Amsterdam, Netherlands: Consumer Safety Institute, 1991 .

5 Ball DJ. Comparative risks and benefits of sport and leisure. University of East Anglia, Norwich, UK: Centre for Environmental and Risk Management, 1997.

6 Hawkins RD, Fuller CW. Risk assessment in professional football. Brf Sports Med 1996;30:165-70

7 Ball DJ, Golob L. Risk ranking. In: Drotz Sjoberg B-M, ed. New risk frontiers. Proceedings of the Society for Risk Analysis 10th Anniversary Conference, Stockholm, Sweden 1997: 606-14.

8 Ball DJ, Goats G. Risk management and consumer safety. International Fournal for Consumer Safety 1996;3:111-24. 